\title{
Exfoliated Graphite Reinforced PMMA Composite: A Study on Nanoindentation and Scratch Behavior
}

\author{
Himel Chakraborty, ${ }^{1}$ Arijit Sinha, ${ }^{1}$ Nillohit Mukherjee, ${ }^{2}$ and Partha Protim Chattopadhyay ${ }^{3}$ \\ ${ }^{1}$ School of Materials Science and Engineering, Bengal Engineering and Science University, Shibpur, Howrah 711103, India \\ ${ }^{2}$ Centre of Excellence for Green Energy and Sensor Systems, Bengal Engineering and Science University, Shibpur, \\ Howrah 711103, India \\ ${ }^{3}$ Department of Metallurgy and Materials Engineering, Bengal Engineering and Science University, Shibpur, Howrah 711103, India
}

Correspondence should be addressed to Nillohit Mukherjee, nilsci@yahoo.co.uk

Received 5 April 2012; Accepted 10 May 2012

Academic Editor: Huisheng Peng

Copyright (C) 2012 Himel Chakraborty et al. This is an open access article distributed under the Creative Commons Attribution License, which permits unrestricted use, distribution, and reproduction in any medium, provided the original work is properly cited.

\begin{abstract}
The present work aims to compare the scratch hardness $\left(H_{s}\right)$ with the indentation hardness $\left(H_{\mathrm{IT}}\right)$ obtained from nanoindentation measurements of exfoliated graphite/poly (methyl methacrylate) (EG/PMMA) composites. EG/PMMA composites with thickness $50 \mu \mathrm{m}$ each were produced by in situ melt mixing method. Scratch hardness was measured from the scratch width formed at low applied load during the course of the scratch measurements. The measured scratch hardness values were compared with the indentation hardness. There is a good correlation between the scratch hardness and the indentation hardness at low indentation depths, with a linear relationship between hardness and the reinforcement content of exfoliated graphite.
\end{abstract}

\section{Introduction}

Nanoindentation has been established as a reliable tool for measuring mechanical properties of polymer composite at the submicron scale [1-6]. An extensive study of nanoindentation on poly (methyl methacrylate) (PMMA) composites has been reported by Jee and Lee $[6,7]$. In nanoindentation, the depth of penetration together with the known geometry of the indenter provide an indirect measure of the projected area of contact at maximum load, and thus hardness is obtained by dividing the maximum applied load by the projected area of contact. In the depth sensing instrumented indentation technique, hardness and elastic modulus can be determined by the Oliver and Pharr model [8-12]. The scratch test is a simple and widely used method for investigating polymer composite surface [13]. In the scratch test an indenter is lowered on to the sample at increasing loads as the indenter tip is moved across the surface of the sample. Scratch hardness can also be measured from the scratch track made by the scratch tester. Scratch hardness has been defined as the load per unit load-bearing area during scratching, taking into account the formation of ridges and a prow. Since it is quite difficult to measure the load-bearing area during the course of scratch experiments, it is calculated from the width of the scratch obtained after the completion of the test $[14,15]$. An advantage of scratch hardness relative to indentation hardness measurements is the possibility of studying the variation of hardness along the length of the scratch. The hardness of different constitute phases can be determined by making one single scratch. The absolute values at specific positions can be calculated by measuring the groove width and by applying the appropriate hardness formula.

\section{Material and Methods}

Commercially available natural graphite flakes (200-300 $\mu \mathrm{m})$ were chemically treated by sintering with $\mathrm{NaOH}$ followed by $10 \% \mathrm{HNO}_{3}$ treatment. Expandable graphite samples from chemically treated graphite $(99.8 \%)$ with nitric acid as an intercalate was prepared as described in [16] and was subjected to a thermal shock at $900^{\circ} \mathrm{C}$ in order to obtain exfoliated graphite (EG). The PMMA pellets were added to the Thermo Haake (Rheomix) and allowed to melt at 


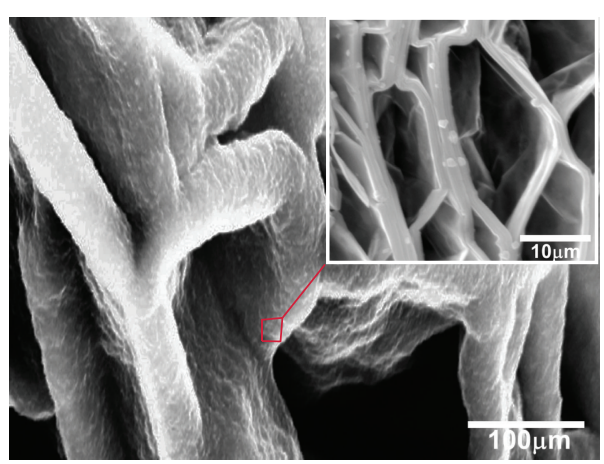

(a)

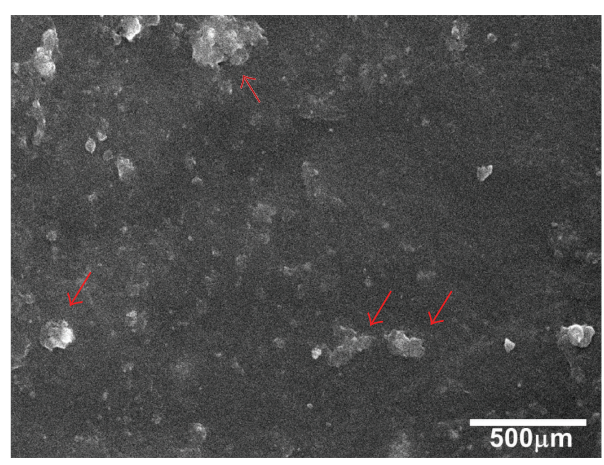

(b)

FIGURE 1: SEM micrographs of (a) exfoliated graphite, (b) 1 wt.\% exfoliated graphite reinforced PMMA matrix.

$220^{\circ} \mathrm{C}$. EG with $0.25,0.5$, and $1 \mathrm{wt} \%$ were then added to the molten PMMA, and dispersion was carried out using high-speed shear mixing with two counter rotating stainless steel sigma shaped rotors at $20 \mathrm{rpm}$. A control sample of neat (i.e., unfilled) PMMA was also subjected to the melt mixing procedure [17] to bring uniformity in the sample preparation technique.

Nanoindentation testing on unreinforced PMMA and EG/PMMA composites samples was carried out using a CSM NHTX S/N: 55-0019 nanohardness tester with a triangular pyramidal diamond indenter (Berkovich, B-I 93, tip radius = $0.2 \mu \mathrm{m}$ (inset of Figure $2(\mathrm{~A}))$ ) under a constant load of $10 \mathrm{mN}$. The Berkovich diamond indenter with total included angle of $142.3^{\circ}$ was used for all the measurements, and the load and displacement resolutions of the instrument were $1 \mu \mathrm{N}$ and $0.03 \mathrm{~nm}$, respectively. The nanohardness tester was calibrated by using glass and fused silica samples for a range of operating conditions. The instrumented hardness $\left(H_{\mathrm{IT}}\right)$ and instrumented elastic modulus $\left(E_{\mathrm{IT}}\right)$ were estimated from the initial gradient of the unloading curves using the Oliver and Pharr [8] model. Five measurements were made at each load on the unreinforced and reinforced PMMA composites.

Scratch testing was carried out on all samples using CSM NST:50-133 nanoscratch tester with a diamond sphero-conical indenter (Ref: SB-A63, $R=2 \mu \mathrm{m}$ ) inside a cantilever (serial number: HL: 126, stiffness: $6.6717 \mathrm{mN} / \mu \mathrm{m}$, $F_{n} D_{Z}$ coefficient at $\left.100 \mu \mathrm{m}: 11.67 \mu \mathrm{m} / \mathrm{V}\right)$ over a scratch distance of $1.0 \mathrm{~mm}$ with a scratch speed of $2 \mathrm{~mm} /$ minutes. The load was increased from 0 to $10 \mathrm{mN}$ at a specified loading rate. A loading rate of $100 \mathrm{mN} / \mathrm{mm}$ was used for the scratch tests. Load can be measured at any place from the loading rate and the length of the scratch track. For indenter tip of circular cross-sectional area (cones, spheres, and parabolas) the equation for scratch hardness is defined as follows $[16,17]$ :

$$
H_{\mathrm{S}}=\frac{8 F_{N}}{\pi b^{2}}
$$

where $F_{N}$ is the applied normal load and $b$ is the scratch track width. All scratches were carried out five times in the same direction. Images of the scratches were obtained using Hitachi S3400N scanning electron microscope (SEM) to measure the width of the scratch tracks.

\section{Results and Discussion}

3.1. SEM Images. Figure 1(a) shows the network-like structure of the exfoliated graphite particles. Large expansions can be seen in the graphite flakes due to the intercalation between the graphite sheets. The higher magnifications image as inset of Figure 1(a) clearly reveals the sheets from the exfoliated graphite with average sheet width of $2 \mu \mathrm{m}$. The void between the sheets was observed mainly due to a greater volume expansion of the exfoliated graphite intercalated compound (GIC).

Figure 1(b) shows the SEM image of the exfoliated graphite reinforced PMMA composite. The exfoliated graphite particulates look like regularly dispersed in PMMA matrix (depicts with arrow marks in Figure 1(b)). However, a tendency towards agglomeration due to increase in exfoliated graphite content in PMMA matrix was also observed.

3.2. Nanoindentation Measurements. In order to investigate the indentation behaviour, unreinforced PMMA and exfoliated graphite reinforced PMMA composites were subjected to the nanoindentation measurement. Figure 2 shows the load-penetration depth curves obtained from unreinforced PMMA and after reinforcing with $0.25,0.5$ and $1 \mathrm{wt} \%$ of EG in PMMA matrix at a maximum load of $10 \mathrm{mN}$. The load-penetration depth behaviour is typical of that for soft materials with a very little signature of an elastic recovery indicating a permanent deformation of the surface beneath the indenter.

The unreinforced PMMA is soft in comparison with the $0.25 \mathrm{wt} \%$ EG/PMMA composite, which has a hardness at around $0.45-0.46 \mathrm{GPa}$. There was an increase in the measured hardness with the increase in reinforcement content. It is also seen that the elastic recovery (area enclosed between the unloading portion of the load-penetration depth profiles and the depth at maximum load) is maximum in the case of 0.5 wt.\% EG/PMMA composite, which indicates an increase in the hardness values as compared to the unreinforced PMMA as clearly revealed from the magnified view 


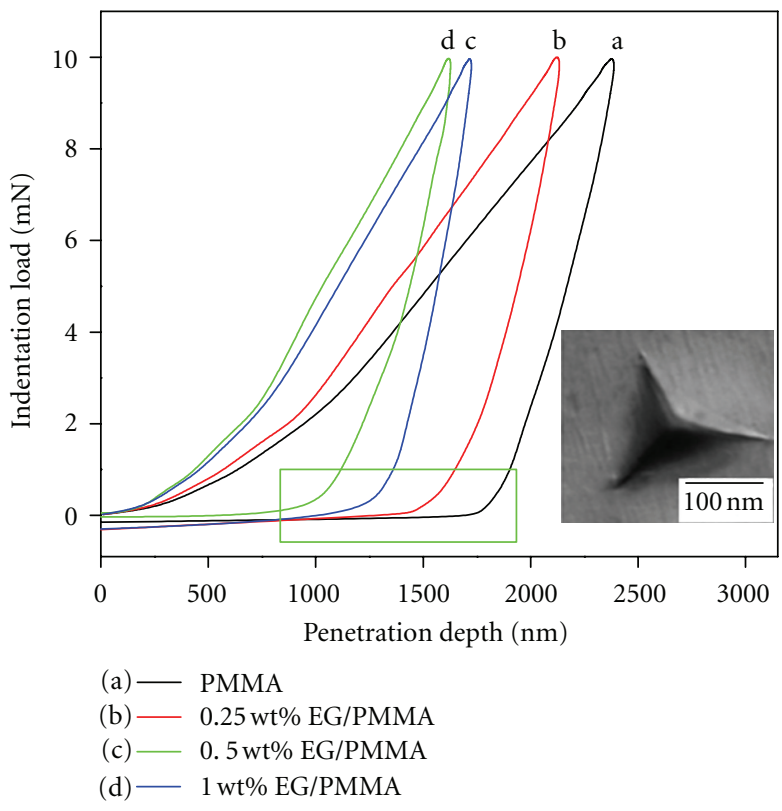

(A)

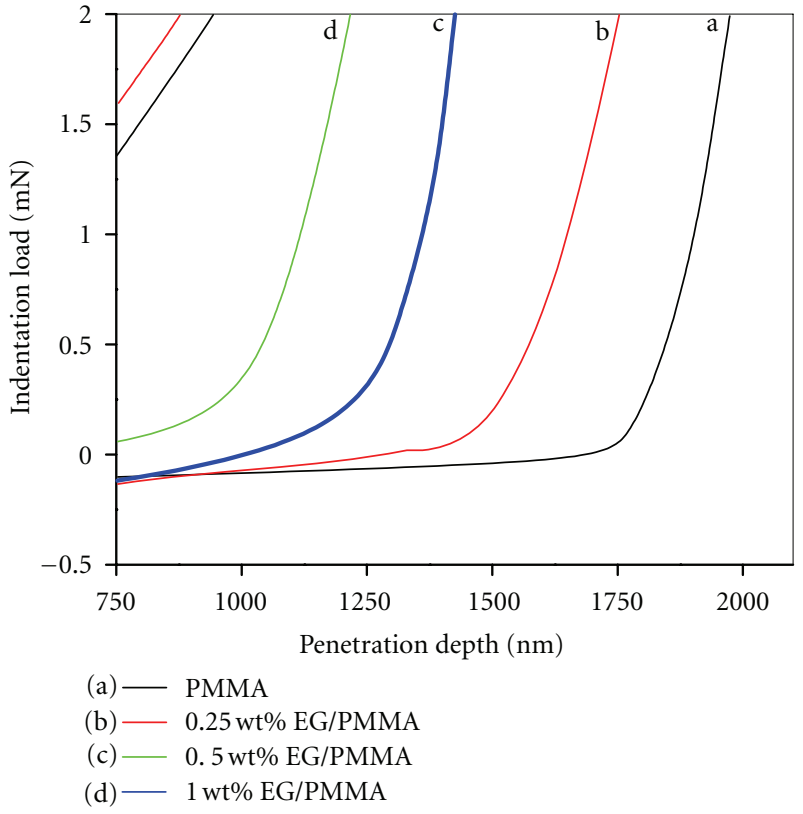

(B)

FIGURE 2: (A) Load-penetration depth curves for unreinforced PMMA and EG reinforced PMMA composites at $10 \mathrm{mN}$ load and (B) enlarge view of the elastic recovery of the unreinforced PMMA and EG reinforced PMMA composites.

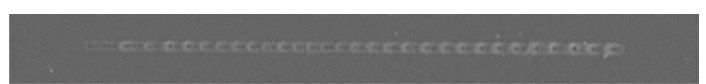

(a)

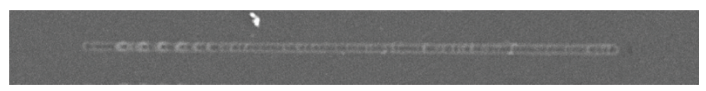

(b)

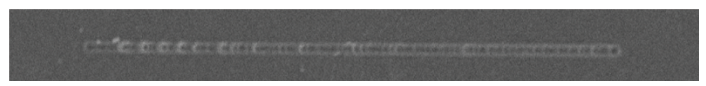

(c)

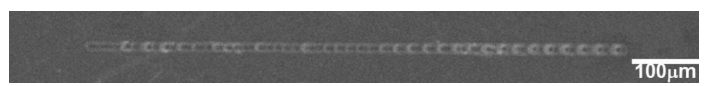

(d)

FIgURE 3: SEM micrographs of scratch deformed surface of (a) unreinforced PMMA, (b) $0.25 \mathrm{wt} \%$ EG/PMMA, (c) $0.5 \mathrm{wt} \%$ EG/PMMA, and (d) $1 \mathrm{wt} \%$ EG/PMMA composites.

(Figure 2(B)) of the bottom portion of unloading loadpenetration depth curves. This is attributed mainly due to the effect of higher EG reinforcement on the measured hardness. For the 1 wt.\% EG/PMMA composite, the elastic recovery is less as compared to the $0.5 \mathrm{wt} . \%$ EG/PMMA composite, which results in lesser hardness values of the same. This might be due to the agglomeration of the reinforced EG (Figure 1(b)) with increase in the content of the reinforcements.

In the scratch test with continues fixed load, initially, the load and depth of penetration were significantly low along the scratch track. The load can be measured at any position along the track and also at any value of loading rate. Figures 3(a)-3(d) compares the SEM images of a scratch track in unreinforced PMMA and after incorporating the different amount of EG in the PMMA matrix. From the SEM images it is possible to obtain valuable information such as the scratch track width and depth of the edge ridges. Scratch track width is measured at a load of $10 \mathrm{mN}$, and from Figures $4(a)-4(d)$ the scratch depths are found to be 9.6, 8.15, 7.89, and $6.73 \mathrm{~nm}$ for unreinforced PMMA and 0.25, 0.5, and $1 \mathrm{wt} \%$ EG/PMMA composites, respectively. The scratch hardness is found using (1) using the applied normal load and the scratch width at that load. In Figures $4(\mathrm{a})-4$ (d) the relation between coefficient of friction (COF) and the scratch depth are shown. It can be observed that the COF reduced with reducing the depth of penetration. On the other hand, with an increase in the amount of EG, both the depth of penetration and COF values were found to decrease more than that of the unreinforced PMMA.

In Figure 5, the calculated scratch hardness $\left(H_{S}\right)$ was compared with the nanoindentation hardness $\left(H_{\mathrm{IT}}\right)$ and the nanoindentation modulus $\left(E_{\mathrm{IT}}\right)$. It was clearly observed that for the unreinforced PMMA and EG/PMMA composites, with the increase in EG content, the trend of scratch and indentation hardness follows the same pattern. But the calculated scratch hardness is found to be higher than the depth sensing instrumented hardness. A good correlation between the scratch hardness and the nanoindentation hardness was found. Both the hardness values increase with an increase in the amount of EG. The indentation modulus is also found to be improved for the EG/PMMA composites more than that of unreinforced PMMA.

\section{Conclusion}

EG/PMMA composites with various amount of reinforcement have been prepared by in situ melt mixing method. 


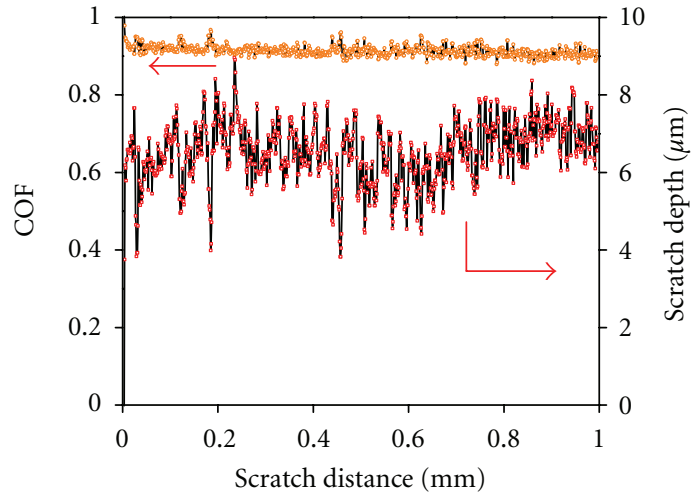

(a)

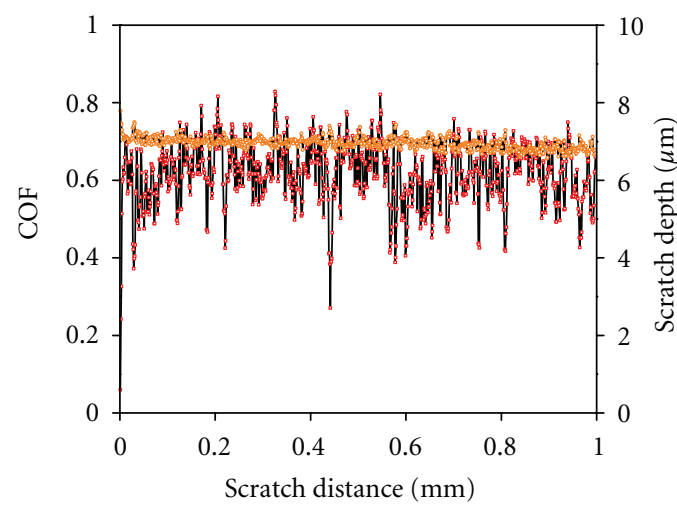

(c)

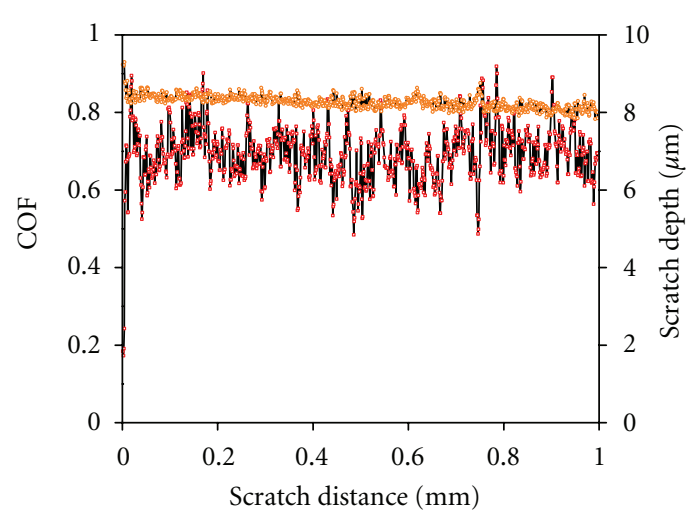

(b)

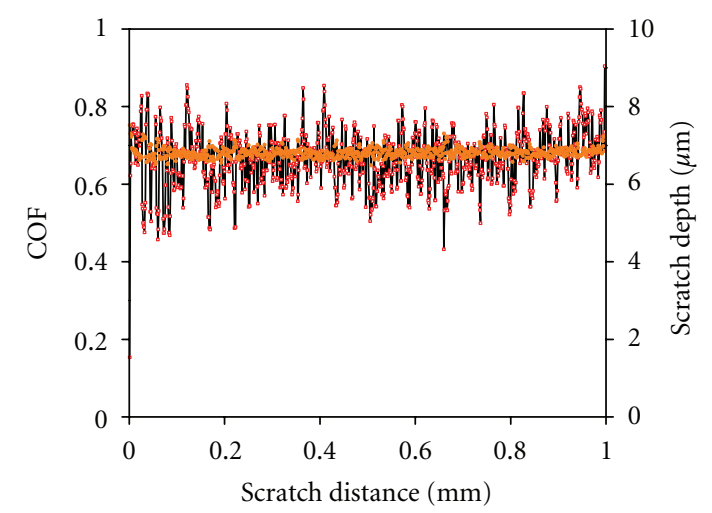

(d)

Figure 4: Variation of coefficient of friction (COF) and scratch depth with scratch distance for (a) unreinforced PMMA, (b) 0.25 wt.\% EG/PMMA, (c) 0.5 wt.\% EG/PMMA, and (d) 1 wt.\% EG/PMMA composites.

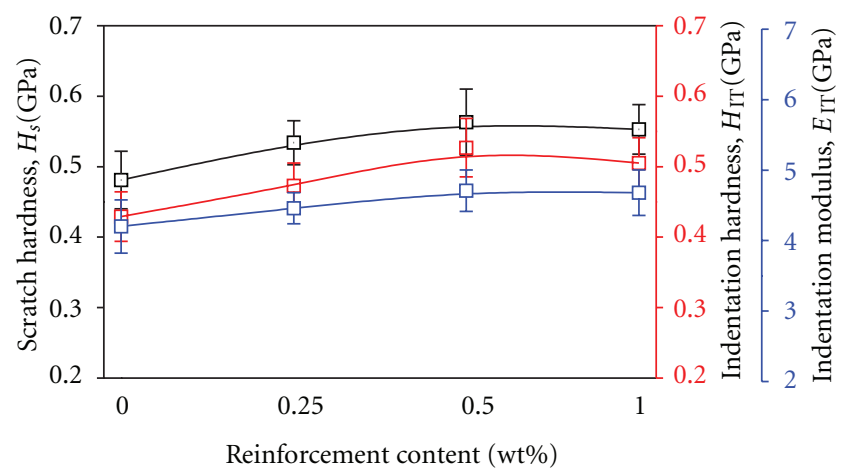

Figure 5: Comparison between the scratch hardness $\left(H_{S}\right)$, indentation hardness $\left(H_{\mathrm{IT}}\right)$ and indentation modulus $\left(E_{\mathrm{IT}}\right)$, for unreinforced PMMA and EG/PMMA nanocomposites.

The hardness and elastic modulus by the nanoindentation technique of the unreinforced PMMA and EG/PMMA composites were measured. Scratch hardness was determined by single pass scratch test using scratch widths. The measured scratch hardness values were compared with conventional nanoindentation hardness and most interestingly it was observed that at lower indentation depth there is a good correlation between the scratch hardness and the nanoindentation hardness.

\section{Acknowledgments}

One of the authors (Himel Chakraborty) is indebted to the Human Resources Development Group, Council for Scientific and Industrial Research (HRDG-CSIR) India, for financial support through Senior Research Fellowship (Award no. 003(0061)2009-EMR-I).

\section{References}

[1] G. Gonçalves, P. A. A. P. Marques, A. B. Timmons et al., "Graphene oxide modified with PMMA via ATRP as a reinforcement filler," Journal of Materials Chemistry, vol. 20, no. 44, pp. 9927-9934, 2010.

[2] D. Stojanovic, A. Orlovic, S. Markovic, V. Radmilovic, P. S. Uskokovic, and R. Aleksic, "Nanosilica/PMMA composites obtained by the modification of silica nanoparticles in a supercritical carbon dioxide-ethanol mixture," Journal of Materials Science, vol. 44, no. 23, pp. 6223-6232, 2009.

[3] M. K. Singh, T. Shokuhfar, J. J. A. Gracio et al., "Hydroxyapatite modified with carbon-nanotube-reinforced poly (methyl methacrylate): a nanocomposite material for biomedical applications," Advanced Functional Materials, vol. 18, no. 5, pp. 694-700, 2008.

[4] M. Tehrani, M. Safdari, and M. S. Al-Haik, "Nanocharacterization of creep behavior of multiwall carbon nanotubes/epoxy nanocomposite," International Journal of Plasticity, vol. 27, no. 6, pp. 887-901, 2011. 
[5] F. Mammeri, J. Teyssandier, C. Connan, E. L. Bourhis, and M. M. Chehimi, "Mechanical properties of carbon nanotubePMMA based hybrid coatings: the importance of surface chemistry," RSC Advances, vol. 2, no. 6, pp. 2462-2468, 2012.

[6] A. Y. Jee and M. Lee, "Mechanical properties of polycarbonate and poly (methyl methacrylate) films reinforced with surfacefunctionalized nanodiamonds," Journal of Nanoscience and Nanotechnology, vol. 11, no. 1, pp. 533-536, 2011.

[7] A. Y. Jee and M. Lee, "Comparative analysis on the nanoindentation of polymers using atomic force microscopy," Polymer Testing, vol. 29, no. 1, pp. 95-99, 2010.

[8] W. C. Oliver and G. M. Pharr, "Improved technique for determining hardness and elastic modulus using load and displacement sensing indentation experiments," Journal of Materials Research, vol. 7, no. 6, pp. 1564-1580, 1992.

[9] W. C. Oliver and G. M. Pharr, "Measurement of hardness and elastic modulus by instrumented indentation: advances in understanding and refinements to methodology," Journal of Materials Research, vol. 19, no. 1, pp. 3-20, 2004.

[10] A. C. Fischer-Cripps, "Critical review of analysis and interpretation of nanoindentation test data," Surface and Coatings Technology, vol. 200, no. 14-15, pp. 4153-4165, 2006.

[11] D. Tranchida and S. Piccarolo, "On the use of the nanoindentation unloading curve to measure the young's modulus of polymers on a nanometer scale," Macromolecular Rapid Communications, vol. 26, no. 22, pp. 1800-1804, 2005.

[12] U. D. Cakmak, T. Schöberl, and Z. Major, "Nanoindentation of polymers," Meccanica, vol. 47, no. 3, pp. 707-718, 2012.

[13] Y. Hu, S. Zhou, and L. Wu, "Surface mechanical properties of transparent poly (methyl methacrylate)/zirconia nanocomposites prepared by in situ bulk polymerization," Polymer, vol. 50, no. 15, pp. 3609-3616, 2009.

[14] M. Sangermano and M. Messori, "Scratch resistance enhancement of polymer coatings," Macromolecular Materials and Engineering, vol. 295, no. 7, pp. 603-612, 2010.

[15] A. Dasari, Z. Z. Yu, and Y. W. Mai, "Fundamental aspects and recent progress on wear/scratch damage in polymer nanocomposites," Materials Science and Engineering, vol. 63, no. 2, pp. 31-80, 2009.

[16] B. J. Briscoe, P. D. Evans, S. K. Biswas, and S. K. Sinha, “The hardnesses of poly (methylmethacrylate)," Tribology International, vol. 29, no. 2, pp. 93-104, 1996.

[17] S. K. Sinha, T. Song, X. Wan, and Y. Tong, "Scratch and normal hardness characteristics of polyamide 6/nano-clay composite," Wear, vol. 266, no. 7-8, pp. 814-821, 2009. 

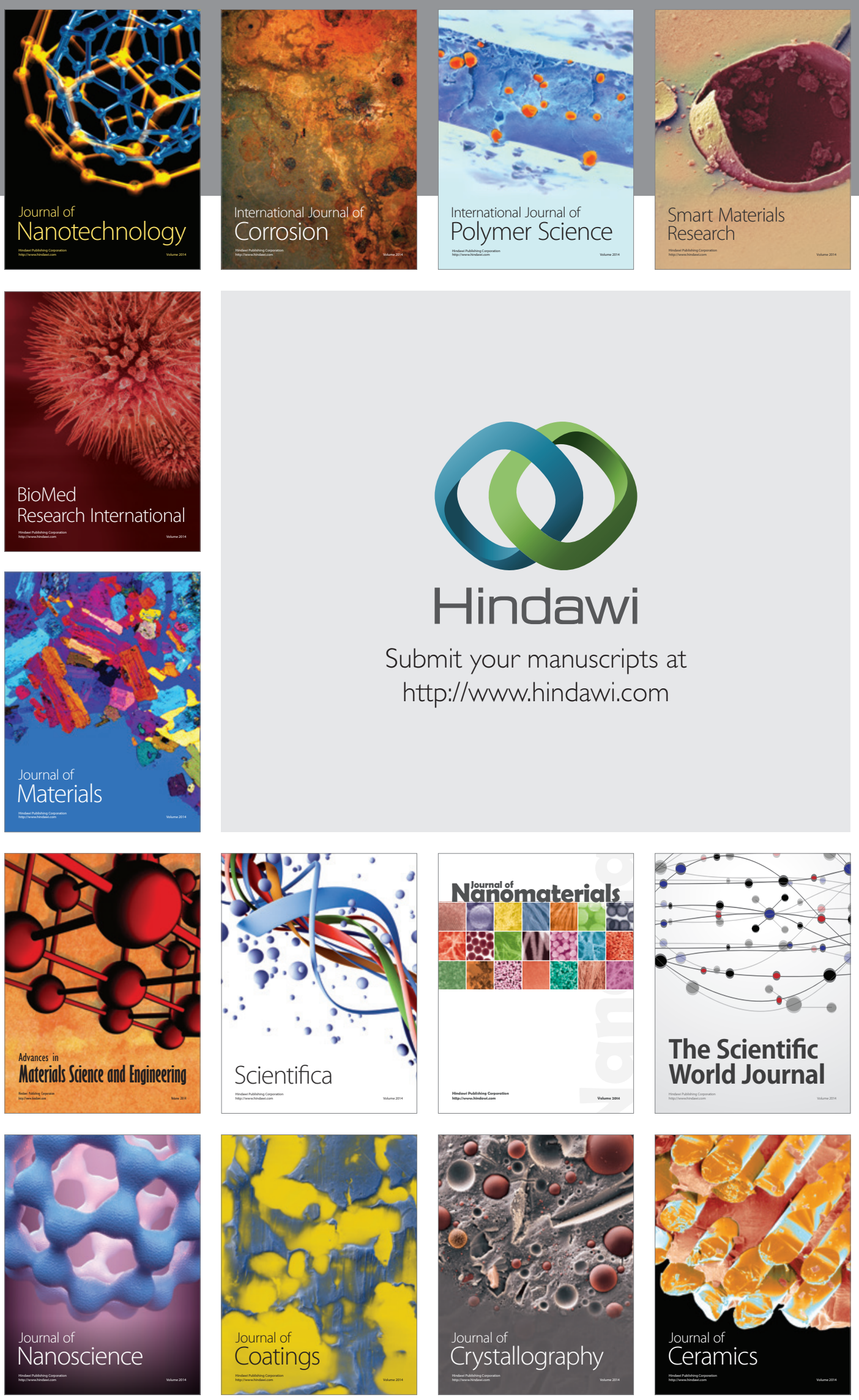

The Scientific World Journal

Submit your manuscripts at

http://www.hindawi.com

\section{World Journal}

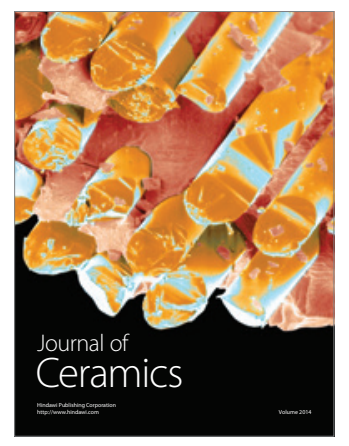

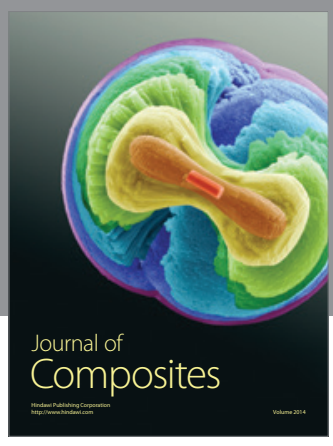
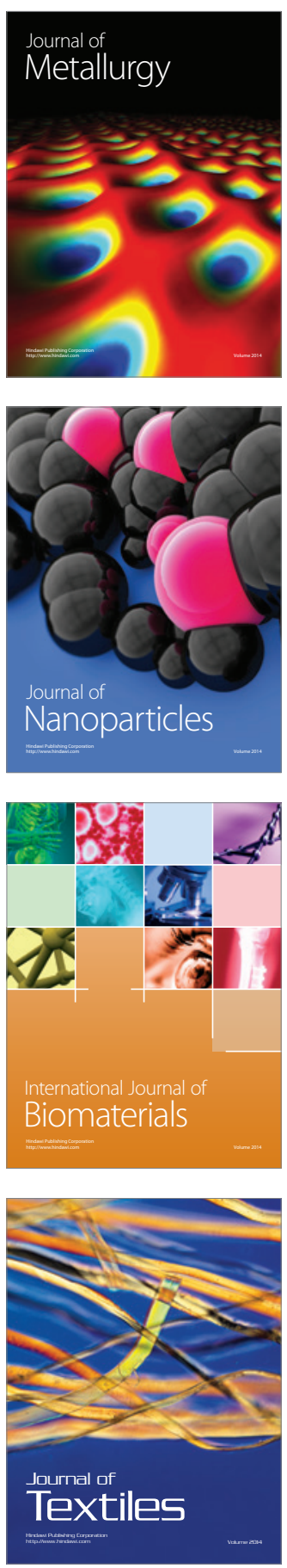